\title{
CANTOS E RECANTOS URBANOS NA LITERATURA DE JOÃO ANTÔNIO
}

\author{
Elena Pajaro Peres* \\ Doutora em História Social pela Faculdade de Filosofia, Letras e Ciências Humanas \\ da Universidade de São Paulo
}

\section{Resumo}

Com os personagens sem paradeiro do escritor João Antônio pode-se compreender a história da transformação urbana de São Paulo a partir dos anos 1950. São migrantes, mestiços, malandros, trabalhadores informais, operários, meninos que surgem e desaparecem pelos cantos de sua literatura e da cidade, traçando uma rota de afetividade e compartilhamento de experiências que pode ser seguida pelo historiador que busca o estudo da cultura em sua vertente não canônica.

\section{Palavras-chave}

Cidade $\bullet$ literatura $\bullet$ história da cultura.

\section{Correspondência}

Av. General Mac Arthur, 540

São Paulo - São Paulo - Brasil

CEP 05338-000

E-mail: epajaroperes@gmail.com

* Este artigo tem como base a pesquisa feita para a tese de doutorado em História Social: Exuberância e invisibilidade. Populações moventes e cultura em São Paulo, 1942 ao início da década de 1970, defendida em 2007 na Universidade de São Paulo e que contou com o apoio financeiro da Fapesp. Na tese, a história de São Paulo é vislumbrada através das obras de Joao Antônio, Carolina Maria de Jesus, Ozualdo Candeias e Plínio Marcos. 


\title{
URBAN CORNERS AND REFUGES IN THE LITERATURE OF JOÃO ANTÔNIO
}

\author{
Elena Pajaro Peres* \\ Ph.D in Social History in Faculdade de Filosofia, Letras e Ciências Humanas of \\ Universidade de São Paulo
}

\begin{abstract}
Through writer João Antônio's unsettled characters one can understand the history of urban transformation of São Paulo beginning in the 1950s. They are migrants, mixed people, rascals, informal workers, workers, children who appear and disappear into the corners of his literature and the city, drawing a route of affectivity and shared experiences that can be followed by the historian who seeks to study the culture under a non canonical view.
\end{abstract}

Keywords

City $\bullet$ literature $\bullet$ cultural history.

\section{Contact}

Av. General Mac Arthur, 540

São Paulo - São Paulo - Brazil

CEP 05338-000

E-mail: epajaroperes@gmail.com

* This article is based on my doctoral thesis "Exuberance and Invisibility. Movable Populations and Culture in São Paulo, 1942 to the beginning of the 1970s", FFLCH-USP, 2007. In that research, that had financial support from Fapesp, I sought to understand the history of São Paulo through the works by Joao Antônio, Carolina Maria de Jesus, Ozualdo Candeias and Plínio Marcos, among other documents. 
João Antônio foi um escritor singular por sua habilidade em percorrer com seus personagens os meandros da cidade. Nascido em São Paulo no ano de 1937, era filho de um português transmontano chegado ainda bebê ao Brasil "e de uma mestiça do Estado do Rio, neta de negros". ${ }^{1}$ Foi morador, durante sua infância e juventude, em vários cantos e recantos para onde carregou o seu lirismo e seu poder de indagação. Podemos segui-lo nessas andanças pelas ruas, através de sua produção escrita que em si é altamente memorialística. Ele escreveu a crônica de sua própria vida ao escrever sobre a cidade de São Paulo, seja em suas "cartas literárias" ou em seus "contos autobiográficos", se assim podemos chamá-los. Mesclou traços de ficção e realidade sem a preocupação em estabelecer uma fronteira nitidamente distintiva entre essas duas dimensões, talvez nisso inspirado por seu mestre maior, a quem dedicou os seus livros: Lima Barreto.

Os estudos literários, desde Benedetto Croce, têm repensado até que ponto é possível isolar tipologicamente os diferentes gêneros sem o perigo de uma sistematização artificiosa que não deixa margem para o diverso, o mesclado, o indefinido. Mário de Andrade, a esse respeito, teceu comentários em carta a Carlos Drumond datada de 1926. Para ele os gêneros:

se baralham, isso até Croce já decretou e está certo. Romances que são estudos científicos, poemas que são apenas lirismo, contos que são poemas, histórias que são filosofia etc. ${ }^{2}$

Essa reflexão é ainda mais imperativa para os historiadores que privilegiam a literatura como fonte para o estudo do cotidiano da cidade, pois, mais importante nesse caso do que a preocupação em categorizar analiticamente a obra de um determinado escritor, classificando-a segundo gêneros literários, é a reconstrução das consonâncias e dissonâncias desses textos criativos com o ritmo espaço-temporal, com o detalhe da vida urbana em seus aspectos descritivos e de experimentação, o que permite uma aproximação indireta do contexto sociopolítico e cultural do período. ${ }^{3}$ Como enunciou o próprio João Antônio sobre seus personagens:

1 ANTÔNIO, João. Paulo Melado do Chapéu Mangueira Serralha. In: Idem. Dedo duro. São Paulo: Cosac Naif, 2003, p. 83. A primeira edição deste texto é de 1982, Editora Record.

2 ANDRADE, Mário de. Carta a Carlos Drumond de Andrade, 1926. In: MORAES, Marcos Antonio de. Orgulho de jamais aconselhar. A epistolografia de Mário de Andrade. São Paulo: Edusp, Fapesp, 2007, p. 111. Neste livro do professor Moraes, também podemos encontrar trechos de uma carta de Mário de Andrade para Fernando Sabino em que o escritor "reitera a opinião em 1942, achando que discutir 'gêneros literários' é 'tema de retoriquice besta', afinal, 'todos os gêneros sempre e fatalmente se entrosaram, não há limites entre eles'.” Idem, p. 111. Segundo Moraes, na própria correspondência do escritor "perdura esse desejo de fluência e de incorporação do diverso que distingue a personalidade do poeta 'trezentos e cinquenta'." Idem, p. 111.

3 Sobre a teoria complexa do tempo e do movimento cf. PRIGOGINE, Ilya. O nascimento do tempo. 
O que se passa com eles e dentro deles, o que se passa na cidade é o que este aqui quis contar. $^{4}$

Por esse motivo, a proposta deste artigo-ensaio é reler a escrita nômade de João Antônio como uma escrita da afetividade, estruturada firmemente na memória. Uma escrita que percorre os cantos e recantos de São Paulo, na segunda metade do século XX, transfigurando-os em refúgios para seus personagens, para si próprio e para o leitor que é convidado a reconhecer a cidade e a reconhecer-se naquela cidade, irremediavelmente inserida num cenário de acelerada transformação. A opção metodológica, nesse sentido, foi buscar uma sincronia com a obra do escritor, deslizando a interpretação por várias de suas produções, inclusive algumas de suas cartas, vistas também como construções literárias, mas tendo como fonte principal o seu conto mais surpreendente "Malagueta, Perus e Bacanaço", publicado em 1963.

Levando em consideração o limite difuso dos gêneros, tão difuso quanto os espaços e tempos percorridos pelos migrantes, mestiços, malandros, trabalhadores informais, operários e meninos que são os personagens de João Antônio, podemos tracejar esses caminhos urbanos, procurando vestígios do cotidiano, das experiências de sobrevivência e criação.

\section{Espiando o cotidiano da cidade}

Tudo teve início no Morro da Geada, na divisa entre as cidades de São Paulo e Osasco, onde viveu seus primeiros anos o menino João Antônio com seu pessoal, como ele dizia, amulatado, mameluco, tangido do Rio de Janeiro pela fome de 1929.

Desde cedo, aprendi a subir ladeira e a pegar bonde andando. Posso dizer, com humildade orgulhosa, que tive morros e bondes no meu tempo de menino. Eu conheci, lá longe, o sol de montanha no Morro da Geada, lá pelos lados do Jaguaré, de onde se avistava, mais à direita, um ponto meio preto, quase azulado, tão vistoso - o pico do Jaraguá. ${ }^{5}$

Nesse morro de migrantes "que não haviam dado certo em parte nenhuma do mundo", para o qual retornaria tempos depois, já como escritor reconhecido,

Tradução de João Gama. Lisboa: Edições 70, 1991. Para uma interpretação profunda da questão do espaço e sua ocupação histórica ver DE CERTEAU, Michel. Practices of space. In: BLONSKY, Marshal (ed.). On signs. Baltimore, Maryland: The Johns Hopkins University Press, 1985.

4 ANTÔNIO, João. Malagueta, Perus e Bacanaço. In: Idem. Malagueta, Perus e Bacanaço. $4^{\mathrm{a}}$. ed. São Paulo: Cosac Naif, 2004, p. 15.

5 ANTÔNIO, João. Meus tempos de menino. In: Idem. A dama do Encantado. São Paulo: Nova Alexandria, 1996, p. 21. 
vivia com liberdade a ponto de não querer descer. ${ }^{6}$ Foi desse morro que escreveu sua primeira carta para a também escritora Ilka Brunhilde Laurito, em 1/09/1959: "Esta carta vem do último subúrbio. Do Morro de Presidente Altino, talvez seu desconhecido". Com essas linhas começou uma grande amizade e uma profícua correspondência que duraria até 1982 . $^{7}$

O Morro da Geada, segundo João Antônio, tinha vários nomes: da Continental, do Wilson, mas o nome oficial e o que ele considerava mais feio era Presidente Altino. ${ }^{8}$ Em seus textos autobiográficos mais de uma vez afirmou:

Subir o morro era fácil; descer, já não era, não. $\mathrm{O}$ coração não pedia pra gente descer. Assim balangando, jongando, arteiro, cheio de marras era o viver espontâneo do morro. Completa liberdade, do balacobaco. ${ }^{9}$

De lá via os espigões da cidade e os arranha-céus que despontavam, enquanto tomava os chás de longa tradição preparados pela bisavó Júlia, uma morena supersticiosa de cabelos muito lisos.

Vó Lula abominava orquídea dentro de casa. Orquídea era mau agouro, vento encanado, fio desencapado, asa negra, ziquizira. ${ }^{10}$

Também tinha o privilégio de conviver com a avó Nair, a filha de Júlia, a sarará de olhos azuis, e mais doze tios e tias-avós. ${ }^{11}$ No morro, além da família extensa, tinha futebol, jogo de malha, criações, só não tinha água encanada, nem TV, nem aparelho de som. A luz era recente. Na memória do escritor, era um morro de batutas. ${ }^{12}$

6 ANTÔNIO, João. No Morro da Geada. In: Idem. Zicartola e que tudo mais vá pro inferno!. São Paulo: Scipione, 1991, p. 9.

${ }^{7}$ As cópias das cartas de João Antônio para a escritora Ilka B. Laurito podem ser encontradas no Arquivo João Antônio, vinculado ao Centro de Documentação e Apoio à Pesquisa da Universidade Estadual Paulista (Unesp), campus de Assis, onde estão separadas em dois volumes: o primeiro de 1959 a 1965 e o segundo de 1965 a 1982. O acervo do escritor encontra-se na Unesp desde 1998. No Departamento de Literatura daquela universidade estão sendo desenvolvidas várias pesquisas de iniciação científica, mestrado e doutorado, a partir desse valioso material. A professora dra. Ana Maria Domingues de Oliveira é quem coordena o arquivo.

8 ANTÔNIO, João. No Morro da Geada. In: Idem. Zicartola e que tudo mais vá pro inferno!, op. cit., p. 7 e 9.

9 ANTÔNIO, João, idem, op. cit., p. 8.

${ }^{10}$ ANTÔNIO, João. Meus tempos de menino. In: Idem. A dama do Encantado, op. cit., p. 21.

${ }^{11}$ À avó Nair Cardoso Gomes, João Antônio dedicou o livro premiado Abraçado ao meu rancor, chamando-a de "heroína do Morro da Geada". Na época, ela estava com 85 anos. O livro também foi dedicado a Lima Barreto. ANTÔNIO, João. Abraçado ao meu rancor. Rio de Janeiro: Guanabara, 1986. Esse livro foi republicado pela editora Cosac Naif em 2001.

${ }^{12}$ ANTÔNIO, João. Meus tempos de menino. In: Idem. A dama do Encantado, op. cit., p. 21-23. 
Ora do lado de lá do rio, ora do lado de cá, sempre seguindo a várzea, João Antônio, entre essas travessias, viveu a partir de 1944 no pedaço chamado de Beco da Onça, na vila Pompeia, na várzea inundável, onde possuíam um pequeno armazém na rua Caióvas (Caiowaa). ${ }^{13}$

O Beco da Onça é getulista, negro, negróide, mestiço, emigrante, cafuso, mameluco, migrante, pobre, operário, corintiano roxo e paulista da gema. ${ }^{14}$

Lá, "deslizava bem" com seu patinete e jogava capoeira com a meninada. ${ }^{15}$ Por incentivo do pai, músico de rodas de chorões e criador de orquídeas, tocava bandolim. Por imposição da mãe, que lhe escondia o instrumento, abandonou a incipiente carreira musical.

Que me lembre. Frequentei de cedo rodas de chorões e seresteiros, levado pela mão de meu pai. O velho sequer tinha escola primária completa. Mas tocava por música. Banjo, violão, cavaquinho, bandolim e os instrumentos de cordas que conheço. Todos.

Atarracado, mãos quadradas e grossas. Mas de onde haveria arrancado aquela sensibilidade? ${ }^{16}$

O córrego Aimberé, que passava ali pertinho, foi aterrado em 1954 pela prefeitura, mais da metade dos casarões velhos do Beco foram demolidos para o surgimento de "prédios de apartamento de bacanas". Mas, então, João Antônio não estava mais naquele canto, mudou-se com a família em 1951 para a Vila Jaguará e depois, em 1953, para a Vila Anastácio, na rua dos Botocudos, perto do depósito municipal de lixo, onde ainda adolescente trabalhou na Anderson Clayton como office boy.

Estudava na Lapa, trabalhou no Armour do Brasil, andava de bicicleta em Moema, frequentava a zona de meretrício e os salões de sinuca do Bom Retiro, fazia artes marciais na Liberdade, arrumou emprego em um banco na Lapa e depois

13 Antes disso seu pai tinha sido funcionário do Frigorífico Armour. Cf. RIBEIRO NETO, João da Silva. João Antônio (Literatura comentada). São Paulo: Abril Educação, 1981, p. 3. Para dados biográficos sobre o autor ver também MAGNONI, Maria Salete. João Antônio. Coleção Rebeldes Brasileiros. Revista Caros Amigos, $\mathrm{n}^{\circ}$ 8, vol. 2. São Paulo: Editora Casa Amarela, s.d. e LACERDA, Rodrigo. João Antônio: Uma biografia literária. Tese de doutorado. Departamento de Teoria Literária e Literatura Comparada, Faculdade de Filosofia, Letras e Ciências Humanas da Universidade de São Paulo, 2006.

14 ANTÔNIO, João. Lambões de caçarola (Trabalhadores do Brasil!). $3^{\mathrm{a}}$ ed. Porto Alegre: L\&PM, 1977. Obs: o livro não possui numeração de páginas.

15 ANTÔNIO, João. Carta para Ilka B. Laurito, 24/08/1960, vol. 1, Arquivo João Antônio, Universidade Estadual Paulista, campus de Assis.

${ }^{16}$ ANTÔNIO, João. Paulo Melado do Chapéu Mangueira Serralha. In: Idem. Dedo duro, op. cit., p. 85. 
numa agência publicitária no centro da cidade, fez o curso normal e a faculdade de jornalismo. No final da década de 1950, mudou-se para o bairro do Jaguaré. ${ }^{17}$ Cursou o Teatro de Arena, também na zona central de São Paulo. Era ouvinte nos cursos de literatura da Faculdade de Ciências Humanas da Universidade de São Paulo na rua Maria Antonia, assistia freneticamente o chamado cinema de arte. ${ }^{18}$

Filho de migrantes, percorreu com a população movente de São Paulo, migrantes, imigrantes e despossuídos, os meandros da cidade numa espécie de "nomadismo urbano", em busca de trabalho, moradia, lazer e estudo. Pelo caminho, depois de deixar o morro, foi criando seus outros "pedaços", seus espaços de afetividade na cidade. ${ }^{19}$ Foi também conhecendo na vida real e recriando na literatura seus malandros e "merdunchos" ou otários.

Trilhou com seu andar, e logo também com sua escrita, as várzeas paulistanas, ocupadas pelas derradeiras hortas, pelo futebol domingueiro, pelas lavadeiras e pelas favelas que começavam a crescer. As várzeas dos rios intimamente chamados pelos moradores pelos nomes próprios: "o Tietê", "o Pinheiros".

Ah, tempos... o Rio Tietê, como o Pinheiros, dava peixe, a gente atravessava os dois de balsa ou de bote, uns caíques que enchiam o coração das velhas de medo e o deste aqui de um tropel. A gente não dizia: o rio, os rios; todos diziam: o Tietê, o Pinheiros. Eles eram tão da gente. ${ }^{20}$

Tinha uma fascinação por esses espaços. Em carta para Ilka B. Laurito de 6/10/61 disse que estava planejando, juntamente com Luis Paulino e Maurice Capovilla, um documentário sobre o rio Tietê e, ainda, com Capovilla um filme de ficção sobre esse rio, cujo título seria A morte dos luminosos. Esses filmes, entretanto, nunca chegaram a ser realizados e o Tietê, cada vez em ritmo mais intenso, perdia sua luz. ${ }^{21}$

${ }^{17}$ RIBEIRO NETO, J. S., op. cit., p. 3-5.

${ }^{18}$ LACERDA, R., op. cit., p. 111. ANTÔNIO, João. Carta para Ilka B. Laurito, 8/08/1960, vol. 1. Arquivo João Antônio, Universidade Estadual Paulista, campus de Assis.

${ }^{19}$ Sobre a noção de "pedaço", ver MAGNANI, José Guilherme Cantor. Festa no pedaço. Cultura popular e lazer na cidade. $3^{\text {a }}$ ed. São Paulo: Hucitec / Unesp, 2003, p. 12. Neste artigo "o pedaço" é entendido como o espaço ou canto onde se deposita a afetividade.

${ }^{20}$ ANTÔNIO, João. Meus tempos de menino. In: Idem. A dama do Encantado, op. cit., p. 21.

${ }^{21}$ João Antônio não fez um filme sobre o Tietê, mas o cineasta Ozualdo Candeias sim, em 1967. No filme A margem, Candeias retrata a várzea como um espaço central e de encantamento, onde somente o tempo presente se manifesta. Cf. PERES, Elena Pajaro. Exuberância e invisibilidade. Populações moventes e cultura em São Paulo, 1942 ao início dos anos 1970. Tese de doutorado em História Social. Departamento de História, Faculdade de Filosofia, Letras e Ciências Humanas da Universidade de São Paulo, 2007. 
Há fartum da refinaria de óleo, das fábricas de maisena, das fundições, dos fósforos da Fiat Lux, do Frigorífico Armour do Brasil, das serrarias, dos esgotos que desembocam e correm grossos, pelo rio Tietê, águas espessas, escuras, encalacradas de entulhos e arruinadas pelo óleo e pelas imundícies. Correm lerdas, pesadas. O rio fedido, a que atiram o nome indígena, é o maior esgoto da cidade.

Nas ruas monturos, proliferam moscas, ratos e insetos ruins. ${ }^{22}$

A várzea, que servia de atalho para as vilas, era cada vez mais cobiçada pela especulação imobiliária industrial e pelo avultamento da malha viária. ${ }^{23}$

Quis seguir estrada, o atalho me surpreendeu. Sapos nas pocinhas das beiradas do campo de futebol. Até há pouco, aquilo era do futebol da molecada. Indústrias querem surgir acompanhando a estrada de ferro, acompanhando tudo, provavelmente serão usinas de concreto. Várzea escura, breu. ${ }^{24}$

Seus personagens aprenderam com ele a andar, rodar, zanzar, zoar, perturbar, varar, ir, voltar, afinar sua arte de chutar tampinhas, fugindo à "semana brava" do subúrbio, porque, como escreveu em uma de suas cadernetas de anotações: "Um dia, como é longo e como passa." ${ }^{25}$ Essa gente, quando cansada, buscava consolo naquilo que a cidade podia oferecer como entretenimento: as vitrines, o passeio pelas ruas, o boteco da esquina. A sessão de cinema era um dos principais escapes, quando se tinha um pouco de capital.

Andando tão devagar. Procurava alguma coisa na tarde. O vento esfriou. Não sabia bem o que, era um vazio tremendo. Mas estava procurando. Os ônibus passavam carregando gente que volta do cinema. Para essa gente de subúrbio mesquinho, semana brava suada nas filas, nas conduções cheias, difíceis, cinema à tarde, pelo domingo é grande coisa. ${ }^{26}$

${ }^{22}$ ANTÔNIO, João. Paulo Melado do Chapéu Mangueira Serralha. In: Idem. Dedo duro, op. cit., p. 101.

${ }^{23}$ Sobre a transformação da várzea do rio Tietê na primeira metade do século XX ver JORGE, Janes. O rio que a cidade perdeu. O Tietê e os moradores de São Paulo, 1890-1940. São Paulo: Alameda Editorial, 2006.

${ }^{24}$ ANTÔNIO, João. Visita. In: Idem. Malagueta, Perus e Bacanaço. $4^{\mathrm{a}}$. ed. São Paulo: Cosac Naif, 2004, p. 117. A primeira edição desse livro é da Editora Civilização Brasileira, 1963.

${ }^{25}$ As cadernetas manuscritas de João Antônio, feitas com embalagens de cigarro, e primorosamente preenchidas com canetas de cores diversas, foram consultadas por mim no Arquivo João Antônio na Universidade Estadual Paulista, campus de Assis. Em carta para Ilka B. Laurito de 24/08/60 escreveu: "sinto uma vontade mesquinha - andar sem quê nem para quê. Rodar, zanzar, zoar, perturbar, ir, voltar, pegar uma rua e ir até seu fim e depois entrar por outra. Outra." Essa carta foi escrita algum tempo depois que a casa do escritor no Jaguaré pegou fogo. Nesse incêndio a família teria perdido todos os seus pertences.

${ }^{26}$ ANTÔNIO, João. Busca. In: Idem. Malagueta, Perus e Bacanaço, op. cit., p. 31. 
Os personagens de João Antônio sentiam febre, "Mas a febre" - explicava - "era febre e queimava e dava pressa." ${ }^{27}$ Essa febre, em sua literatura híbrida, transformava-se em deambulação poética pela cidade cinzenta. Em 1959, escreveu para sua amiga Ilka:

Mas um fato vai ficando líquido - andam matando a poesia das coisas. No entanto, parece-me que Calíope é bastante persistente e não morre mesmo. Então, coitadinha, Calíope moderna já não pode estar nas coisas belas, que as belas coisas andam mirradas. Calíope gruda-se, então, nas feiuras e tristezas de um modo de poeira cinzenta, chaminés, arranha-céus, gente tonta lá embaixo, gente nos aviões a jato, na poeira, solidão, atribulação, tristeza e nada. ${ }^{28}$

Seu primeiro livro, Malagueta, Perus e Bacanaço, publicado em 1963, traz um conjunto de contos que, escritos no final dos anos 1950 e início da década de 1960, traduzem esse sentimento de busca por algo, busca aparentemente indefinida. ${ }^{29}$ Acima de tudo são contos de deriva que têm na andança o ponto central. ${ }^{30}$ Nessa deriva incessante por São Paulo, por suas várzeas e colinas, seus personagens - migrantes, mestiços, malandros, trabalhadores informais, soldados, operários, meninos -, como também o próprio João Antônio, foram demarcando os seus "pedaços".

Atravessei a ponte. Tinha trocados no bolso, me enfiaria num trem, acabaria na estação Júlio Pestes. (...) Eu queria andar.

Desde que papai morreu, esta mania. Andar. ${ }^{31}$

Eles não observam o ambiente, o que eles fazem é percorrer as ruas conferindo sentidos, deixando marcas, às vezes interferindo, participando. Estão predispostos a isso por serem desenraizados. Vagueiam e aproveitam os acasos. ${ }^{32}$

${ }^{27}$ ANTÔNIO, João. Malagueta, Perus e Bacanaço. In: Idem. Malagueta, Perus e Bacanaço, op. cit., p. 189.

${ }^{28}$ ANTÔNIO, João. Carta para Ilka B. Laurito, 20/09/1959, $1^{\circ}$ vol. Arquivo João Antônio, Universidade Estadual Paulista, campus de Assis.

${ }^{29}$ O livro Malagueta, Perus e Bacanaço publicado em 1963 está dividido em três partes: Contos gerais, Caserna e Sinuca. A primeira parte é composta pelos seguintes contos: Busca, Afinação da arte de chutar tampinhas e Fujie. Caserna tem Retalhos da fome numa tarde de G. C. e Natal na cafua. A última parte: Frio, Visita, Meninão do caixote e o conto principal Malagueta, Perus e Bacanaço. O livro ganhou dois Prêmios Jabuti: Revelação de Autor e Melhor Livro de Contos, além de outros prêmios. Para as citações utilizei a quarta edição da Cosac Naif, 2004.

${ }^{30}$ Entende-se deriva aqui no sentido situacionista de Guy Debord. Segundo Anselm Jappe, as derivas "são passeios de mais ou menos um dia durante os quais a pessoa 'se entregava às solicitações do lugare dos encontros'.” JAPPE, Anselm. Guy Debord. Tradução de Iraci D. Poleti. Petrópolis: Vozes, 1999, p. 83.

${ }^{31}$ ANTÔNIO, João. Busca. In: Idem. Malagueta, Perus e Bacanaço, op. cit., p. 27.

${ }^{32}$ Para a diferença entre a flanerie de Baudelaire e Walter Benjamin e a dérive situacionista de Guy 
Um sujeito solícito me enche o copo. Encosto-me ao balcão, fico olhando para a calçada, onde besouros caem e gente passa de longe em longe. Remato a bebida, saio. E agora, o quê? Cinema? Meio tarde para cinema. ${ }^{33}$

Como não jogaram âncoras em lugar algum, todo lugar pode ser investido de profundo sentimento, desde que permita a intervenção pessoal e coletiva - $o$ que se tornava cada vez mais difícil em uma cidade constantemente invadida pela intervenção oficial e, mais ainda, pela intervenção especulativa do mercado.

A dificuldade para os personagens de João Antônio, entretanto, parece estar no ponto da dimensão coletiva, na qual não conseguem se inserir. Eles são solitários, são seres esquivos que não se deixam conhecer por completo. Possuem uma subjetividade poderosa e sentem a falta do reconhecimento na grande cidade movente. João Antônio, porém, se reconhecia neles e em São Paulo. Neles encontrava seu espaço de solidariedade e com eles reconhecia a cidade que não parava de mudar.

Realmente não fui eu que os criou. A vida foi quem me deu. Deu por dar, simplesmente. Deu de graça, de presente. Eu os conheço todos eles e elas ainda vivem por aí e se agitam, se arrastam nas ruas. Todos, todas. Vagabundos, meninos, meninas, malandros, adúlteras, toda uma cambada de marginais, que a vida tem me dado de presente sem que eu pedisse. Mas eu os amo e os quero como se fossem meus filhos. E não posso tratá-los como padrasto. ${ }^{34}$

No conto "Busca", o protagonista, um operário pobre, ex-boxeador, narra sua errância numa tarde domingueira pela cidade, buscando um preenchimento que não encontra. O tédio que parece carregar, entretanto, não traz como alicerce uma dúvida metafísica, é, pelo contrário, bem calcado no "pedregulho mal socado da rua", onde o sapato novo "subia, descia" e seu enternecimento pelo cair da tarde rapidamente é suspenso pela urgência das tarefas diárias, como tirar o limo do tanque encardido em que sua mãe lavava as roupas da família. Tarefas que, contudo, nunca eram cumpridas devido ao improviso da vida. Improviso que João Antônio sabia perceber muito bem. ${ }^{35}$

Debord, cf.. SEVCENKO, Nicolau. Dérive poética e objeção cultural. Literatura e sociedade. São Paulo: Departamento de Teoria Literária e Literatura Comparada, FFLCH-USP, número 7, 2003 2004, p. 16-34. José Pereira da Silva Neto, em seu trabalho de crítica literária, também concluiu que nos contos de João Antônio não se trata de flanerie. SILVA NETO, José Pereira da. O espaço urbano de São Paulo no realismo ficcional de João Antônio. Dissertação de mestrado. Departamento de Literatura, Faculdade de Ciências e Letras da Universidade Estadual Paulista, campus de Assis, 2002.

33 ANTÔNIO, João. Visita. In: Idem. Malagueta, Perus e Bacanaço, op. cit., p. 115.

${ }^{34}$ ANTÔNIO, João. Carta para Ilka B. Laurito, 20/09/1959, vol. 1. Arquivo João Antônio, Universidade Estadual Paulista, campus de Assis.

${ }^{35}$ ANTÔNIO, João. Busca. In: Idem. Malagueta, Perus e Bacanaço, op. cit. 
E essa prática do caminhar pela cidade dos personagens de João Antônio dava aos sapatos um destaque particular, eles recebem uma atenção muito especial: novos, de borracha, de couro, emitindo o "plac-plac" na calçada, cheios de pó denunciando a falta de calçamento na várzea, rudes coturnos da caserna, tênis enlameados, chinelos, os tênis furados do pequeno engraxate no conto "Frio", 36 sapatos furados de Malagueta, sapatos brilhantes do malandro Bacanaço, pés descalços dos meninos da vila.

Não posso falar dos meus sapatos de saltos de couro... Nas minhas andanças é que sei! Só eles constatam, em solidão, que somente há crianças, há pássaros e há árvores pelas tardes de sábados e domingos, nesta minha cidade. ${ }^{37}$

Sapatos cheios de pó, sapatos cheios de pó, vivem sempre empoeirados. Porcaria de vila! ${ }^{38}$

Contudo, para ver os sapatos, objeto de distinção num país de passado escravocrata onde poucos podiam andar calçados, era preciso abaixar o olhar. ${ }^{39}$ Do alto do morro, desde cedo, João Antônio aprendeu mais do que olhar para baixo. Aprendeu como olhar por baixo, prestando atenção onde pisava, enxergando o cotidiano da cidade e as tampinhas que poderiam ser chutadas, afinando a arte, como o personagem de seu conto de rara inspiração. ${ }^{40}$

Há algum tempo venho afinando certa mania. Nos começos chutava tudo o que achava. A vontade era chutar. Um pedaço de papel, uma ponta de cigarro, outro pedaço de papel. Qualquer mancha na calçada me fazia vir trabalhando o arremesso com os pés. Depois não eram mais papéis, rolhas, caixas de fósforos. Não sei quando começou em mim o gosto sutil. Somente sei que começou. E vou tratando de trabalhá-lo, valorizando a simplicidade dos movimentos, beleza que procuro tirar dos pormenores mais corriqueiros da minha arte se afinando. ${ }^{41}$

${ }^{36}$ ANTÔNIO, João. Frio. In: Idem. Malagueta, Perus e Bacanaço, op. cit., p. 103.

${ }^{37}$ ANTÔNIO, João. Afinação da arte de chutar tampinhas. In: Idem. Malagueta, Perus e Bacanaço, op. cit., p. 43.

${ }^{38}$ ANTÔNIO, João. Visita. In: Idem. Malagueta, Perus e Bacanaço, op. cit., p. 118.

${ }^{39}$ Maria Cristina Cortez Wissenbach abordou em um de seus estudos a importância dos sapatos para a população negra liberta, uma vez que na escravidão eles se constituíam em objeto interdito. WISSENBACH, Maria Cristina Cortez. Ritos de magia e sobrevivência. Sociabilidades e práticas mágicoreligiosas no Brasil (1890/1940). Tese de doutorado em História Social. Departamento de História, Faculdade de Filosofia, Letras e Ciências Humanas da Universidade de São Paulo, 1997, p. 24.

40 '“(...) it is below - 'down'- on the threshold where visibility ends that the city's common practitioners $d$ well. The raw material of this experiment are the walkers, 'Wandersmanner', whose bodies follow the cursives and strokes of an urban 'text' they write without reading."Cf. CERTEAU, Michel de. Practices of space. In: BLONSKY, Marshal (ed.). On signs. Baltimore, Maryland: The Jonhs Hopkins University Press, 1985, p. 124.

${ }^{41}$ ANTÔNIO, João. Afinação da arte de chutar tampinhas. In: Idem. Malagueta, Perus e Bacanaço. $4^{\mathrm{a}}$ ed., op. cit., p. 41. 
Chutar qualquer coisa e de qualquer forma era um indício do inconformismo sempre presente em sua literatura, mas o preciosismo de afinar a arte e especializar-se no alvo demonstrava habilidade e astúcia. Para chutar com graça era preciso coordenar o corpo com o olhar deslizante, ajustar o seu desejo ao calçamento da cidade e assim, metaforicamente, limpar o espaço para as pisadas de quem desceu do morro e quis ver como era a vida por baixo.

Às espiadelas, o menino João Antônio foi percebendo o que estava interdito, mas que, por isso mesmo, era mais tentador: as pernas das moças no bonde, que aprendeu a olhar com o tio, as tacadas certeiras nas mesas de sinuca, proibidas para sua idade. ${ }^{42}$

Nem dá pra esquecer o tio alto, o ainda tio-avô Rubens, mulherengo de topo, bigode frajola, pobre, carioca, porém caprichoso nas roupas, empaletozado como na época, empertigado, namorador impenitente e alegre e, pioneiro, a me ensinar nos bondes a olhar as pernas nuas das mulheres e, após, lhes oferecer o lugar. ${ }^{43}$

Seus personagens também utilizavam o olhar indireto, por baixo.

Espiando maroteiras no bar do Tico, bebendo misturas, ouvindo casos, um dia. Um é o primeiro. Nos fundos, havia duas mesas de sinuca e depois, em noite alta, a conversa continuava lá. Uma vez, catei o taco. Sem acreditar que viciasse. ${ }^{44}$

O menino, protagonista do conto, aprendeu a admirar o jogo malandro nos intervalos de suas brincadeiras ou quando roubava um pouco do tempo de suas idas à vendinha para buscar leite a pedido de sua mãe. Aproveitava então o tempo para vaguear por aí. Nos dias de chuva, o caminho se tornava muito mais atrativo, "o tênis pisava na água, pisava no barro, pisava na água, pisava no barro, pisava na água, pisava no barro, pisava... - Dá um litro de leite". Como não tinha, foi preciso ir até o bar desconhecido e o acaso da tempestade fez com que por lá se demorasse um pouco mais.

\footnotetext{
${ }^{42}$ Aos 16 anos, João Antônio foi surpreendido pela polícia jogando sinuca no bar do Tico, como fazia todos os fins de semana à noite. Esse episódio deixou seu pai desconsolado. Cf. RIBEIRO NETO, J. S., op. cit., p. 4.

43 ANTÔNIO, João. Meus tempos de menino. In: Idem. A dama do Encantado, op. cit., p. 22.

${ }^{44}$ ANTÔNIO, João. Paulo Melado do Chapéu Mangueira Serralha. In: Idem. Dedo duro, op. cit., p. 108.
} 
No Paulistinha havia sinuca e só então eu notei. Pedi uma beirada no banco em volta da mesa, ajeitei o litro de leite entre as pernas.

- Posso espiar um pouco?

Um homem feio, muito branco, mas amarelado ou esbranquiçado, eu não discernia, um homem de chapéu e de olhos sombreados, os olhos lá no fundo da cara, braços finos, tão finos, se chegou para o canto e largou um sorriso aberto:

- Mas é claro, garotão! $!^{45}$

E assim, meio por acidente, com um pouco de sorte, habilidade e muita astúcia, o meninão tornou-se um ás na sinuca, um imbatível jogador. Tudo aprendido em silêncio a partir da primeira espiadela e depois seguindo, "resvalando, sorrateiro" pela madrugada, escorregando seu olhar pelo pano verde. Porque os personagens de João Antônio nunca miram, eles escorregam ou dançam o olhar, como o malandro Bacanaço, afinados com as táticas de sobrevivência na cidade:

Os olhos dançaram no brilho dos sapatos, foram para as cortinas verdes. ${ }^{46}$

Seus personagens são os andarilhos que escrevem o "texto urbano", que não é feito de palavras, mas de passos, de chutes sutis, de entradas e saídas, de recuos, de rastros, de deslizes do corpo e dos olhares, de tacadas precisas como numa mesa de sinuca. Traçavam a dança dos viradores, pelas ruas atrás de parceiros para o jogo, mas também de algo mais. O peregrinar não é composto somente pelo que estava faltando e era preciso buscar, mas é a própria substância de uma cultura.

Vestido de branco, com macio rebolado, Bacanaço se chegou:

- Olá, meu parceirinho! Está a jogo ou está a passeio ${ }^{47}$

João Antônio assombrava-se com a cidade. ${ }^{48}$ Mas, nos seus andaços, como sua mãe gostava de dizer, o que mais importava eram os pequenos espaços de viração. ${ }^{49} \mathrm{O}$ detalhe importava-lhe mais do que o todo. O gesto mais do que a explicação racionalizada. $\mathrm{O}$ afeto do lugar, mais do que a composição da paisagem. Entretanto, a confusão do mundo o perturbava e esta confusão vinha da cidade vista como um todo, como desabafou com Ilka no início dos anos 1960:

${ }^{45}$ ANTÔNIO, João. Meninão do caixote. In: Idem. Malagueta, Perus e Bacanaço, op. cit., p. 129.

${ }^{46}$ ANTÔNIO, João. Malagueta, Perus e Bacanaço. In: Idem. Malagueta, Perus e Bacanaço, op. cit., p. 149.

47 ANTÔNIO, João. Idem, ibidem.

${ }^{48}$ ANTÔNIO, João. Carta para Ilka B. Laurito, 6/06/60, $1^{\circ}$. vol. Arquivo João Antônio, Universidade Estadual Paulista, campus de Assis.

${ }^{49}$ ANTÔNIO, João. Carta para Ilka B. Laurito, 5/09/61, $1^{\circ}$. vol. Arquivo João Antônio, Universidade Estadual Paulista, campus de Assis. 
São Paulo é uma cidade terrível.

Já a chamaram de uma porção de nomes bonitos e razoáveis, mas nunca disseram que São Paulo é uma cidade terrível. Engalanaram São Paulo várias vezes, desonestamente. E terrível é desde as quatro horas da manhã em que já é varrida, andada, rodada, bicicleteada por uma casta valorosa que se apressa aos bondes, aos lotações, aos papa-filas. Os trabalhadores. Empurrando e empurrados e sem falar. Este convívio ciclópico, maquinal, ganha dimensão vertiginosa; contamina, se alastra. Às nove horas já é tudo confusão.

Não é otimismo.

\section{Em São Paulo não se anda. Nas ruas de São Paulo as pessoas correm e os lentos são contaminados, empurrados, levados em multidão...}

Ninguém o conhece, ninguém se sabe, ninguém se tem.

A competição irracional se repete todos os dias, todos, e o indivíduo se envenenando. Aos domingos, feriados, dias santos de guarda; dias de repouso? Pausa do delírio? Nada disso. (...)

Ah, São Paulo! Dura e triste e sem remédio a solidão constante de suas multidões... ${ }^{50}$

Era terrível essa cidade, especialmente porque obrigava a pensar na passagem do tempo. Era uma cidade que apontava insistentemente para a irreversibilidade, para o ganho e para a perda. Os migrantes urbanos, que se constituíam na matéria da literatura de João Antônio, tinham uma forte noção desse tempo que não volta. $\mathrm{O}$ deslocamento para quem estava em movimento era sempre mais temporal do que espacial. Quando se voltavam para olhar o que antes ali estivera, percebiam que já não estava mais e isso denotava passagem de tempo. O espaço era o mesmo, mas transformado. ${ }^{51}$

Por isso, para apreender essa cidade, era preciso fragmentá-la, apreciá-la por partes, conhecê-la no seu mínimo de tempo-espaço e em suas durações. É isso

\footnotetext{
${ }^{50}$ ANTÔNIO, João. Recado de São Paulo. Texto sem data anexado à carta para Ilka B. Laurito, julho de 1960, Arquivo João Antônio, Universidade Estadual Paulista, campus de Assis.

${ }^{51}$ O físico químico Ilya Prigogine salienta a importância de sua experiência de emigrado no seu trabalho sobre o tempo e sua irreversibilidade. Cf. PRIGOGINE, Ilya. O nascimento do tempo, op. cit., p. 19. Pude constatar em meu trabalho com depoimentos de imigrantes que eles têm sempre uma forte consciência da realidade do tempo, pois na experiência da migração o deslocamento espacial é reversível, mas nunca o temporal. Como exemplo dessa situação posso relatar casos de imigrantes galegos no Brasil que deixaram para trás, na Espanha, casas centenárias construídas de pedras, resistentes ao tempo. Esses imigrantes, quando para lá retornaram em visita, após décadas de ausência, tiveram uma experiência de choque. As casas lá permaneciam, o espaço era o mesmo, mas totalmente transfigurado pelo tempo. O envelhecimento do próprio imigrante e das pessoas com quem convivera talvez seja o principal elemento desse choque. Cf. PERES, Elena Pajaro. A inexistência da terra firme. A imigração galega em São Paulo, 1946-1964. São Paulo: Edusp/Fapesp/Imesp, 2003.
} 
que ocorre em um de seus contos de maior expressão: "Malagueta, Perus e Bacanaço". Os três malandros, numa noite de sábado, percorrem um itinerário que começa e termina no bairro da Lapa, formando uma espécie de círculo mágico que sai da várzea em direção à colina, para depois retornar ao mesmo lugar. É um conto de duração e de tempo, aponta para um desfecho e retorna depois de concluído o contorno. ${ }^{52}$

O engraxate batucou na caixa mostrando que era o fim.

Bacanaço se levantou, estirou uma nota ao menino. Os olhos dançaram no brilho dos sapatos, foram para as cortinas verdes. ${ }^{53}$

Assim começa o percurso do mestiço Bacanaço e seus aliados, o jovem Perus e o velho Malagueta, que se encontravam diariamente na entrada do salão de sinuca Velho Celestino, na beira da estação do trem, ao lado do Mercado da Lapa. ${ }^{54}$ Esse encontro se deu naquele dia sob os olhos do pequeno engraxate, que provavelmente ali ficou, a tudo assistindo, às espiadelas, em meio à agitação do final da tarde, com os mascates com suas carrocinhas ou panos no chão, apregoando suas mercadorias, quinquilharias sem fim, a rua suja e estreita, a porteira fechada, a algazarra, circulação, bondes lotados, buzinas, homens engravatados ou não, bicicletas, motonetas, caminhões, pedintes, muita gente vinda da Lapa de baixo, vinda do Moinho Velho, do Piqueri, de Cruz das Almas, de Vila Anastácio para o cinema, todo iluminado. Barulho de locomotiva, meninos jornaleiros gritando, choro de criança querendo sorvete. "A Lapa fervia." "A rua parece inchar." 55

${ }_{52}$ Como escreveu Wallerstein: "nem o acontecimento efêmero e microscópico nem a realidade eterna e infinita, cujo conceito é duvidoso, oferecem foco útil para uma análise inteligente. Se devemos alcançar uma compreensão significativa da realidade, convém mais nos determos no terreno do que designara como o terceiro não-excluído, simultaneamente tempo e duração, um particular e um universal, que são simultaneamente os dois termos e nenhum deles". WALLERSTEIN, Immanuel. O tempo, a duração e o terceiro não-excluído: reflexões sobre Braudel e Prigogine. In: LOPES, Marco Antônio (org.). Fernand Braudel. Tempo e história. Rio de Janeiro: FGV, 2003, p. 75.

${ }^{53}$ ANTÔNIO, João. Malagueta, Perus e Bacanaço. In: Idem. Malagueta, Perus e Bacanaço, op. cit., p. 149.

${ }^{54}$ A Lei Municipal no 3.908, de 1/07/50, assinada pelo prefeito Lineu Prestes, criou o Mercado Distrital da Lapa que continua em atividade até os dias atuais.

${ }^{55}$ ANTÔNIO, João. Malagueta, Perus e Bacanaço. In: Idem, op. cit., p. 155-156. O menino engraxate poderia ser o sr. E. N., trabalhador do Mercado da Lapa, a quem pedi informações em dezembro de 2004 em busca do salão Velho Celestino, do cinema, enfim da ambiência do conto de João Antônio. Ele indicou onde ficavam os estabelecimentos e compôs com sua narrativa o cenário da Lapa nos anos 1950, quando era um menino da favela do Piqueri, a mesma em que morava o personagem Malagueta. Não sabe ler e disse não conhecer os contos de João Antônio, mas afirmou que conheceu de vista o malandro jogador de sinuca "Carne Frita", citado pelo autor, como também os afamados contraventores Isaquinho, Esquerdinha e Sete-Dedos. Costumava engraxar sapatos na porta do Velho Celestino por alguns trocados. Cf. PERES, Elena Pajaro. Exuberância e invisibili- 
Os malandros estavam quebrados e combinaram rodar por todos os muquinfos da cidade, Água Branca, Pompeia, Pinheiros, Mooca, Penha, Limão, Tucuruvi, Osasco... Ganhariam o jogo no embuste. "Virariam São Paulo de pernas para o ar. ${ }^{" 56}$ A ordem era transgredir, virar, inverter, e começariam pelo salão Joana d'Arc na Água Branca.

Um bairro após o outro, os personagens vagantes de João Antônio vão esquadrinhando a cidade, reconhecendo todos os bilhares, estudando o jogo, vasculhando as ruas. Eram reconhecidos também: “- Ô...”, saudação típica entre os tacos muito falados. Nas calçadas, pessoas sentadas balançando os chinelos, cachorro, tempo para lembranças. Até chegarem na cidade na hora "muito safada dos viradores", a madrugada. ${ }^{57}$ Após serem humilhados pelo tira Silveirinha no salão Paratodos, tiveram que ouvir a risada terrível que se espalhara pelo largo Santa Ifigênia com um "sentir de quem perdeu". É nesse momento que, de cima do viaduto, Perus vê o vale.

Visto de cima, o Vale do Anhangabaú era um silêncio grande de duas tiras pretas de asfalto. O menino Perus olhou. Lindo, o Vale, aquele silêncio de motonetas paradas, de árvores e de carros em solidão. Lua lá em cima, o menino olhou. Já se percebia, à frente, o contorno do Mosteiro de São Bento também sossegado no seu jeito antigo. Luz elétrica dos postes jogava uma calma... ${ }^{58}$

Por um curto instante, um encantamento surge no conto e o tempo estanca, mas não são os arranha-céus ao redor que isolados provocam a emoção, nem o viaduto velho, que por ser velho ficava solene, nem o mosteiro sossegado sozinho. Esses elementos apenas compõem o cenário quando em conjunto e preparam a cena, intensificando o conflito, matizando, denunciando tempo e duração, "o viaduto velho, prédios novos", o vale. O vale é para onde se dirige o olhar. Mas é só um instante mínimo, quase imperceptível, mas profundo. Em seguida os vagabundos entreolharam-se, reconhecendo-se e lá embaixo um automóvel roncou firme, fazendo o tempo novamente rodar. Eles sabiam e acreditavam que "Haveria jogo em algum canto. Faziam fé." ${ }^{59}$ Como Augusto Matraga de Guimarães Rosa, cada um pensava por si: "a minha vez vai chegar."

dade. Populações moventes e cultura em São Paulo, 1942 ao início dos anos 1970, op. cit., p. 121.

${ }^{56}$ ANTÔNIO, João. Malagueta, Perus e Bacanaço. In: Idem. Malagueta, Perus e Bacanaço, op. cit., p. 163.

${ }^{57}$ ANTÔNIO, João. Malagueta, Perus e Bacanaço. Idem, p. 184.

${ }^{58}$ ANTÔNIO, João. Malagueta, Perus e Bacanaço. Idem, p. 197.

59 ANTÔNIO, João. Malagueta, Perus e Bacanaço. Idem, p. 201.

${ }^{60}$ ROSA, João Guimarães. A hora e vez de Augusto Matraga. In: Idem. Sagarana. Rio de Janeiro: 
No final do conto, Perus novamente fica enternecido, agora com o nascimento do dia, e de novo cai no jogo, volta a dançar, chamado pelos parceirinhos. Num primeiro momento o que o encanta é a sensação de silêncio e quietude, nada funcionando, tudo parado, tempo parado, tempo encantado no vale. No final do conto, entretanto, o encantamento vem da certeza da passagem do tempo, o surgimento de um novo dia, que poderia trazer mudanças, mas que lhe dava a tranquilidade do tempo cíclico que se abria para novas aventuras. Tudo estava perdido. Nada estava perdido.

A história prossegue até o desfecho final que não é fim, é retorno, à Lapa, onde tudo começaria novamente. Como também, sempre, na vida de João Antônio. Em um texto autobiográfico recordou a cidade através de seus passos:

É andar. E andar.

Osasco, Lapa, Vila Ipojuca, Água Branca, Perdizes, Barra Funda, Centro, Pinheiros, Lapa, na volta. Roteiro é este, com alguma variação para as beiradas das estações de ferro, dos cantos da Luz, dos escondidos de Santa Ifigênia. Também um giro lá por aquele U, antigamente famoso, que se fazia entre as ruas Itabocas e Aimorés, na fervura da zona do Bom Retiro. ${ }^{61}$

Percebe-se assim que o livro e o conto "Malagueta, Perus e Bacanaço" são o traçado ficcional do roteiro afetivo autobiográfico do autor. Aqueles cantos pelos quais passava e, em movimento, deixava sua inscrição, são os mesmos em que seus personagens o acompanham. João Antônio não quis seguir só, organizou o espaço de acordo com o seu afeto e estabeleceu um roteiro de cantos, conduzindo sua escrita como quem conduz seus passos pela cidade.

A cidade de São Paulo dos recantos tortos, nos quais seu personagem Paulinho duma Perna Torta "tortamente" vagava, com sua caixinha de engraxate, lustrando os passos dos outros e aprendendo a viver no movimento como milhares de meninos, mas ao mesmo tempo sendo diferente.

Mas nas minhas perambulagens aprendi a ver as coisas. Cada rua, cada esquina tem sua cara. E cada uma é cada uma, não se repete mais. Aprendi. ${ }^{62}$

Paulinho tinha suas preferências: "Gosto mais da rua Barão de Paranapiacaba." Mas sabia descrever todas as ruas do seu roteiro afetivo. Conferindo-lhes uma personalidade própria. 
A rua Direita tem movimento demais. Perturbada pelos seus sujeitos gritando: "burro, cavalo e cobra", seus cambistas, seus camelôs, seus marreteiros de gasparinos e rifas de automóveis (...). ${ }^{63}$

Eram ruas difíceis de percorrer, como a própria vida dos personagens de João Antônio, mas que tinham em si o encanto da cidade, que o autor soube levar para o Rio de Janeiro quando para lá se mudou em 1968.

Na década de 1980, João Antônio recordaria a mesma e, ao mesmo tempo, diferente São Paulo, lamentando sua plastificação, a perda das singularidades. Como era difícil reconhecer essa transformação, para alguém que aprendera a perambular pelos caminhos e que experimentara no decorrer dessas andanças o gosto pelo diverso. ${ }^{64}$

Vou, venho e me atrapalho, a cidade me foge. O que estas ruas, esquinas, praças me dão, dão noutra cidade, não minha; esta nada tem a ver. Também me falta, agora, intimidade para reavê-la. Houve, alguma coisa rompeu. ${ }^{65}$

Entretanto, mesmo apontando em seus últimos escritos, publicados nos livros Abraçado ao meu rancor e $A$ dama do Encantado, ${ }^{66}$ o que considerava uma lamentável perda de referenciais, pelo crescimento desmedido e a interpenetração de elementos mais intensos de controle e ordenação, ele ainda reconhecia essa cidade como sua. Após anos de vida no Rio de Janeiro, voltou sua escrita a São Paulo, seus cantos e recantos, de maneira cuidadosa e apressada, para abraçar-se novamente a sua afetividade, muito mais do que ao seu rancor.

Mas que eu não a achincalhe, afinal, fonte de ternura e, no fundo, comoção de antigamente, ela é uma cidade. Todos têm a sua e nasceram numa. Esta é a minha, queira ou não. Mais que geografia, um modo de vida. ${ }^{67}$

Brasileira, 1975, p. 69. Esse conto foi publicado pela primeira vez em 1965 no livro Os dez mandamentos. Coletânea de Contos e Novela. Rio de Janeiro: Civilização Brasileira. Depois foi revisto pelo autor entre maio e junho de 1970 enquanto se encontrava internado no Sanatório da Tijuca no Rio, o mesmo em que ficara o escritor Lima Barreto.

${ }^{63}$ ANTÔNIO, João. Paulinho Perna Torta. Idem, p. 69.

${ }^{64} \mathrm{O}$ professor Alfredo Bosi, no primoroso prefácio que fez para a primeira edição do livro Abraçado ao meu rancor, comparara nesse aspecto João Antônio ao escritor Lima Barreto. BOSI, Alfredo. Um boêmio entre duas cidades. In: ANTÔNIO, João. Abraçado ao meu rancor. Rio de Janeiro: Guanabara, 1986.

${ }^{65}$ ANTÔNIO, João. Abraçado ao meu rancor. In: Idem. Abraçado ao meu rancor, op. cit., p. 116

${ }^{66}$ Este último publicado no ano de sua morte, 1996.

${ }^{67}$ ANTÔNIO, João. Abraçado ao meu rancor. In: Idem. Abraçado ao meu rancor, op. cit., p. 94. 


\section{Referências bibliográficas}

ANTÔNIO, João. Abraçado ao meu rancor. Rio de Janeiro: Guanabara, 1986.

ANTÔNIO, João. A dama do Encantado. São Paulo: Nova Alexandria, 1996.

ANTÔNIO, João. Dedo duro. São Paulo: Cosac Naif, 2003.

ANTÔNIO, João. Lambões de caçarola (Trabalhadores do Brasil!). $3^{\text {a }}$ ed. Porto Alegre: L\&PM, 1977.

ANTÔNIO, João. Leão de chácara. Rio de Janeiro: Civilização Brasileira, 1975.

ANTÔNIO, João. Malagueta, Perus e Bacanaço. 4a ed., São Paulo: Cosac Naif, 2004.

ANTÔNIO, João. Zicartola e que tudo mais vá pro inferno! São Paulo: Scipione, 1991.

BOSI, Alfredo. Um boêmio entre duas cidades. In: ANTÔNIO, João. Abraçado ao meu rancor. Rio de Janeiro: Guanabara, 1986.

DE CERTEAU, Michel. Practices of space. In: BLONSKY, Marshal (ed.). On signs. Baltimore, Maryland: The Johns Hopkins University Press, 1985.

JAPPE, Anselm. Guy Debord. Tradução de Iraci D. Poleti. Petrópolis: Vozes, 1999.

JORGE, Janes. O Rio que a cidade perdeu. O Tietê e os moradores de São Paulo, 1890-1940. São Paulo: Alameda Editorial, 2006.

LACERDA, Rodrigo. João Antônio: Uma biografia literária. Tese de doutorado. Departamento de Teoria Literária e Literatura Comparada, Faculdade de Filosofia, Letras e Ciências Humanas da Universidade de São Paulo, 2006.

MAGNANI, José Guilherme Cantor. Festa no pedaço. Cultura popular e lazer na cidade. $3^{\mathrm{a}}$ ed. São Paulo: Hucitec / Unesp, 2003.

MAGNONI, Maria Salete. João Antônio. Coleção Rebeldes Brasileiros. Revista Caros Amigos, ${ }^{\circ}$ 8, vol. 2. São Paulo: Editora Casa Amarela, s.d.

MORAES, Marcos Antonio de. Orgulho de jamais aconselhar. A epistolografia de Mário de Andrade. São Paulo: Edusp, Fapesp, 2007.

PERES, Elena Pajaro. Exuberância e invisibilidade. Populações moventes e cultura em São Paulo, 1942 ao início dos anos 1970. Tese de doutorado em História Social. Departamento de História, Faculdade de Filosofia, Letras e Ciências Humanas da Universidade de São Paulo, 2007.

PERES, Elena Pajaro. A inexistência da terra firme, a imigração galega em São Paulo, 1946-1964. São Paulo: Edusp/Fapesp/Imesp, 2003.

PRIGOGINE, Ilya. O nascimento do tempo. Tradução de João Gama. Lisboa: Edições 70, 1991.

RIBEIRO NETO, João da Silva. João Antônio (Literatura comentada). São Paulo: Abril Educação, 1981.

ROSA, João Guimarães. A hora e vez de Augusto Matraga. In: Idem. Sagarana. Rio de Janeiro: Nova Fronteira, 2001. 
SEVCENKO, Nicolau. Dérive poética e objeção cultural: da boemia parisiense a Mário de Andrade. Literatura e sociedade. São Paulo: Departamento de Teoria Literária e Literatura Comparada, FFLCH-USP, número 7, 2003-2004, p. 16-34.

SILVA NETO, José Pereira da. O espaço urbano de São Paulo no realismo ficcional de João Antônio. Dissertação de mestrado. Departamento de Literatura, Faculdade de Ciências e Letras da Universidade Estadual Paulista, campus de Assis, 2002.

WALLERSTEIN, Immanuel. O tempo, a duração e o terceiro não-excluído: reflexões sobre Braudel e Prigogine. In: LOPES, Marco Antônio (org.). Fernand Braudel. Tempo e história. Rio de Janeiro: FGV, 2003.

WISSENBACH, Maria Cristina Cortez. Ritos de magia e sobrevivência. Sociabilidades e práticas mágico-religiosas no Brasil (1890/1940). Tese de doutorado em História Social. Departamento de História da Faculdade de Filosofia, Letras e Ciências Humanas da Universidade de São Paulo, 1997.

Recebido: 18/02/2010 - Aprovado: 24/02/2011 